Flora (198x) 180: $377-390$

VEB Gustav Fischer Verlag Jena

\title{
Der Stickstoffhaushalt immergrüner mediterraner Hartlaubblätter
}

\author{
St. Diamantoglot und L. Kitu. \\ Institut für Allgemeine Botanik d. $\mathbf{r}$ Universität Athen, Griechenland und Biologisches Institut \\ der Universität Stuttgart, Bundesrepublik Deutschland

\section{Seasonal Variations of Nitrogen Components in Mediterranean Evergreen Sclerophyllous Leaves}

\begin{abstract}
Summary
The seasonal variations of major nitrogenous components (total $\mathrm{N}$, protein $\mathrm{N}$, soluble $\mathrm{N}$ ) in sclerophyllous leaves of four mediterranean species - Ceratonin siliqun, Olea europaea var. sylvestris, Pistacin lentiscus and Quercus coccifern - were investigated throughout the whole lifetime of the leaves. The leaf-longevity of the first two species mentioned is about two years, that of the latter two species is somewhat longer than one year. As reference values the raw fibre content and the total chlorophyll content of the leaves were also measured. The raw fibre content increases during leaf-growth, there-after it remains constant. In the leaves having a lifetime of two years, in the spring of the second year an additional increase, although weak, is observed. The chlorophyll content rises during the leaf growth, then remains unchanged for some time, but begins to decrease early. In the leaves of Cerutonin and Olen the shrinkage is recognized already in the spring of the second year. During the period of senescence, the decrease of chlorophyll a is more distinct than that of chlorophyll b.

The total $\mathrm{X}$ content in all cases decreases during leaf-growth and then remains constant. In Cerutoniu leaves it is reasonably high considering that it is an evergreen species. Rather early the $\mathrm{X}$-content begins to decrease; which is intensified during the last months of the lifetime of the leaves. This is due to the well-known export of $\mathrm{X}$-compounds from senescent tissues. In Ceratonin leaves the $\mathcal{N}$-content increases during the first winter; obviously they serve as $\mathrm{N}$ storage organs. The content of protein- $\mathrm{N}$ in all species shows esssentially the same variations as that of total $\mathrm{X}$.

Results of tests carried out in the months of January and August revealed that the proline content in the leaves of all species is higher during the drought period than during the cold period. ¿sing the different reference-values, the variations of $\mathrm{N}$-content during leaf longevity of the four species are discussed in connection with reflections on maintenance costs.
\end{abstract}

\section{Einleitung}

Bei unseren bisherigen Lntersuchungen zur Ökophysiologie der Stoffspeicherung in mediterranen Hartlaubpflanzen (Diamaxtogror \& KILI 1982, dort weitere Lit.) wurde der Stickst offhaushalt nicht einbezogen. Erstaunlicherweise gibt es bisher kaum Lntersuchungen dazu: einige neuere Arbeiten liegen allerdings von Arten aus der konvergenten Hartlaubvegetation des kalifornischen Chaparral vor (MooNEY \& RINDel 1979: Gímox 1983: Merixo et al. 1984). Sogar die Lebensdauer der Blätter von Hartlaubpflanzen des Mittelmeergebiets wurde am natürlichen Standort erst neuerdings genau festgestellt (Diamaxtoglot \& Mitrakos 1981). Da der Stickstoffhaushalt der Blätter in engem Zusammenhang mit Entwicklungs- und Alterungsvorgängen steht (¿'bersicht bei Thomas \& Stondart 1980), wurde er nunmehr während der ganzen Lebensdauer der Blätter von 4 mediterranen Hartlaubarten untersucht. Als Bezugsgrößen wurden neben der Trockenmasse auch die Größen 
Rohfasergehalt und C'hlorophyllgehalt der Blätter herangezogen. Seit Mothes (1931) ist hekannt, da B der Stickstoffhaushalt von Blättern durch Wassermangel erheblich beeinfluBt wird (C'bersicht bei BradFord \& Hsiao 1982). Von besonderem Interesse war es daher, festzustellen, welche Auswirkungen die Sommertrockenheit am Standort auf den $\mathrm{X}$-Haushalt mediterraner Hartlaubblatter hat.

\section{Material und Methoden}

\section{Interial}

Untersucht wurden Blatter von C'eintoniu siliqun L., Olea europuea L. var. sylvestris Brot. (- ssp. olenster Hofr.. et LiNk), Ptstacin lentıscus L. und Quercus coccifera L. Das Material wurde bei C'eratonia einem etwa $3,5 \mathrm{~m}$ hohen Baum, bei den underen 3 Arten jeweils Strauchern von ungefahr $1 \mathrm{~m}$ Hohe entnommen. Alle Pflanzen wuchsen in offenen Gelande nahe dem Institut fur Allgemeine Botanik der Cniversitat Athen und wurden nicht bewassert. Die Standorte befinden sich in einer naturlichen Phrygana an einem westgeneigten Hang am Fuße des $\mathrm{Hymettos}$

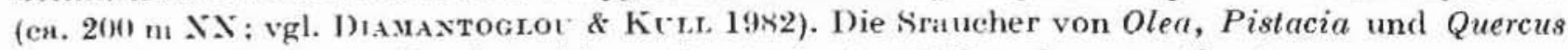
stehen einunder unnuttelbar benachbart, Cerutonia et wa $800 \mathrm{~m}$ davon ent fernt.

Die Temperatur- und Niederschlagsverhalt nisse in Ernte zeitraum 197x-1980 sind in Abb. 1 dargestellt. Die Dauer der Trockenzeit in den Sommern 1978 und 1979 betrug jeweils ungefahr 3 Monate. Frost trat um Stundort in beiden Wintern an 5 d auf.

\section{Methoden}

Ernte des Materials: Die Blatter wurden ab Marz 1978 (Beginu des Neutriebs) in monatlichen Abstanden wahrend der ganzen Lebensdauer von Blattern an einer größeren Zuhl gekennreichneter Sprosse geerntet, bis die Blattzahl gleichartiger Kontroll-Sprosse infolge des Blattfalls unter $20 \%$ der unfanglich gebildeten Blatter abgesunken war. Zu diesem Zeitpunkt waren die geernteten Blatter bereits verfarbt und bei Quercus auch zum Teil vom Rand her abgestorben. Ein Teil der Blatter wurde sofort in Plastikbeuteln 10 min in kochendes Wasser gehalten und unschließend bei $60{ }^{\circ} \mathrm{C}$ in einem Ventilutort rockenschrunk getrocknet. Ein weiterer Teil wurde eingefroren und bei $-20{ }^{\circ} \mathrm{C}$ bis zur Cntersuchung a uf bewahrt.

Bestimmungsverfuhren. Die Bestimmung des Gesamtstickstoffs erfolgte nach KJELDAHL (1 $\times \times 3$ ), ebenso die Bestimmung des Protein-Stickstoffs nuch Fallen der Proteine mit Trichloressigsaure. Die Differenz von Gesanit-N und Protein-N wird als , ,löslicher Stickst off" bezeichnet (vgl. Horiwarth 1976). Die Prolinbestimnung (Stıchproben vom Sommer und vom Winter) erfolgte nuch der Methode von Bates et al. (1973). Die Messung der C'hlorophyll- und der Rohfasergehulte wurden nach dem bei Stтевік: (1965) angegebenen Verfuhren durehgefuhrt.

Zur Wussergehaltsbestimmung wurden die Blatter nuch dem Abtoten bei $80{ }^{\circ} \mathrm{C}$ bis zur Gewichtskonstunz getrocknet.

In Bodenproben erfolgten die quantitative Bestimmung von $\mathrm{N}$, $\mathrm{K}$, С $\mathrm{Cu}$ u $\mathrm{Mg}$ flammenphotonetrisch uns dem Gesamtaufschluß nit $\mathrm{HNO}_{3} / \mathrm{H}_{2} \mathrm{O}_{2}$; die Messung von Nitrat und Phosphat

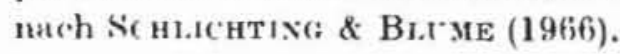

\section{Ergebnisse}

\section{Lebensdauer und Wassergehalt der Blätter}

Die Lehensdauer der Blatter der untersuchten Arten ist bei DIAMantoglou \& Mitrakos (1981) beschrieben. Die fiur jene Cntersuchungen herangezogene Ceratonia-Pflanze ist mit der hier verwendeten identisch; die 3 anderen Arten hingegen wurden damals an einer anderen Stelle untersucht. Die Blatter von Ceratonia und Olea leben ungefahr 2 Jahre; jene von Quercus coccifera und Pistacuia lentiscus etwas länger als ein Jahr (vgl. Abb. 2). Das Flachenwachstum der Blätter wird bei allen 4 Arten im Verlauf des Monats Juli abgeschlossen. Die Veränderungen der Blattwassergehalte sind in Abb. 2 dargestellt. Während des Blattwachstums nehmen die Wassergehalte naturgemả ab. Ab August (nur bei Quercus schon früher) werden 


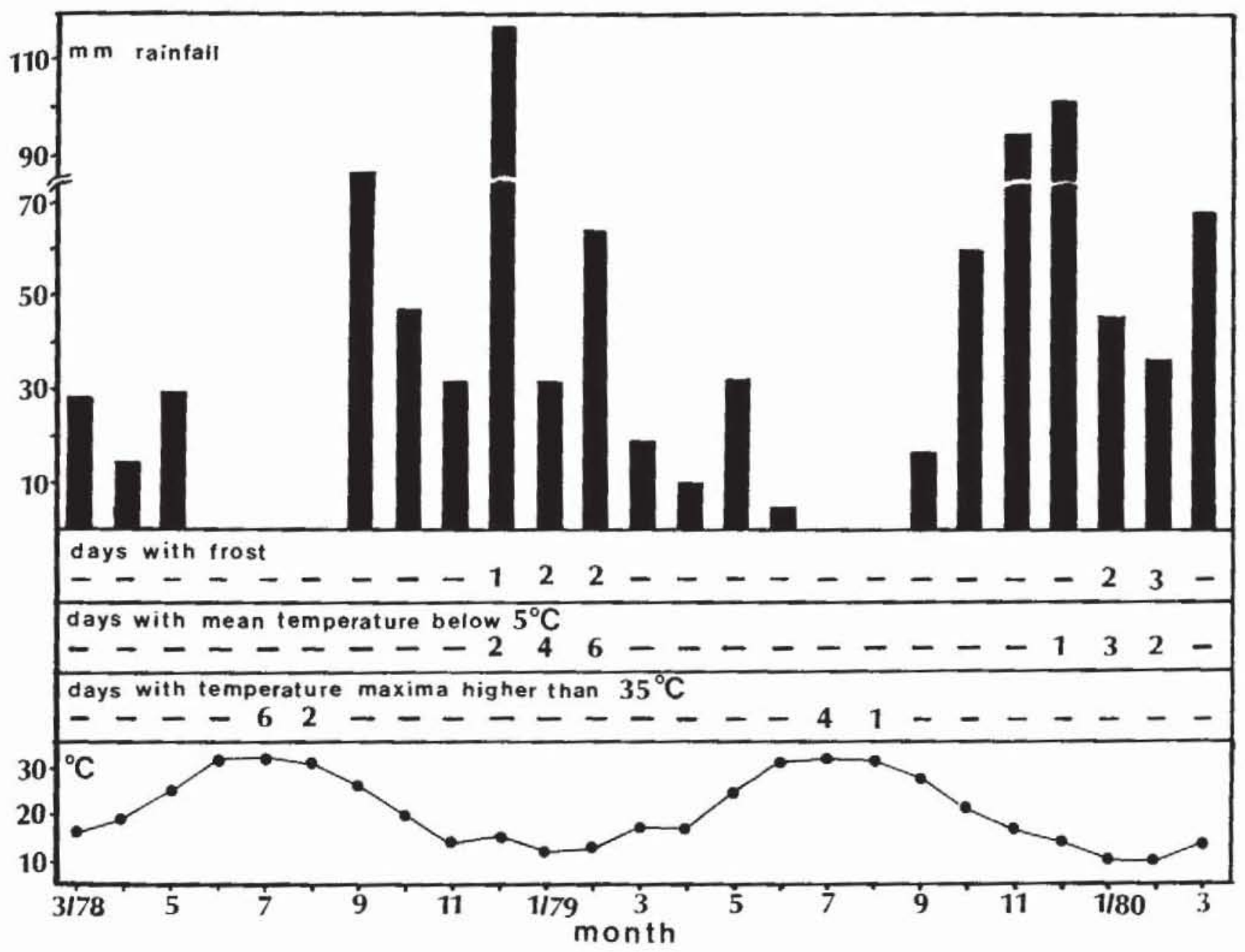

Abb. 1. Klimadaten in Lntersuchungszeitraum.

Oben: Monatsniederschlage; unten: Monatsmittel der Temperaturen.

Fig. 1. Clinatic duta for the period of investigations.

Top: monthly rainfall; bottom: monthly mean temperatures.

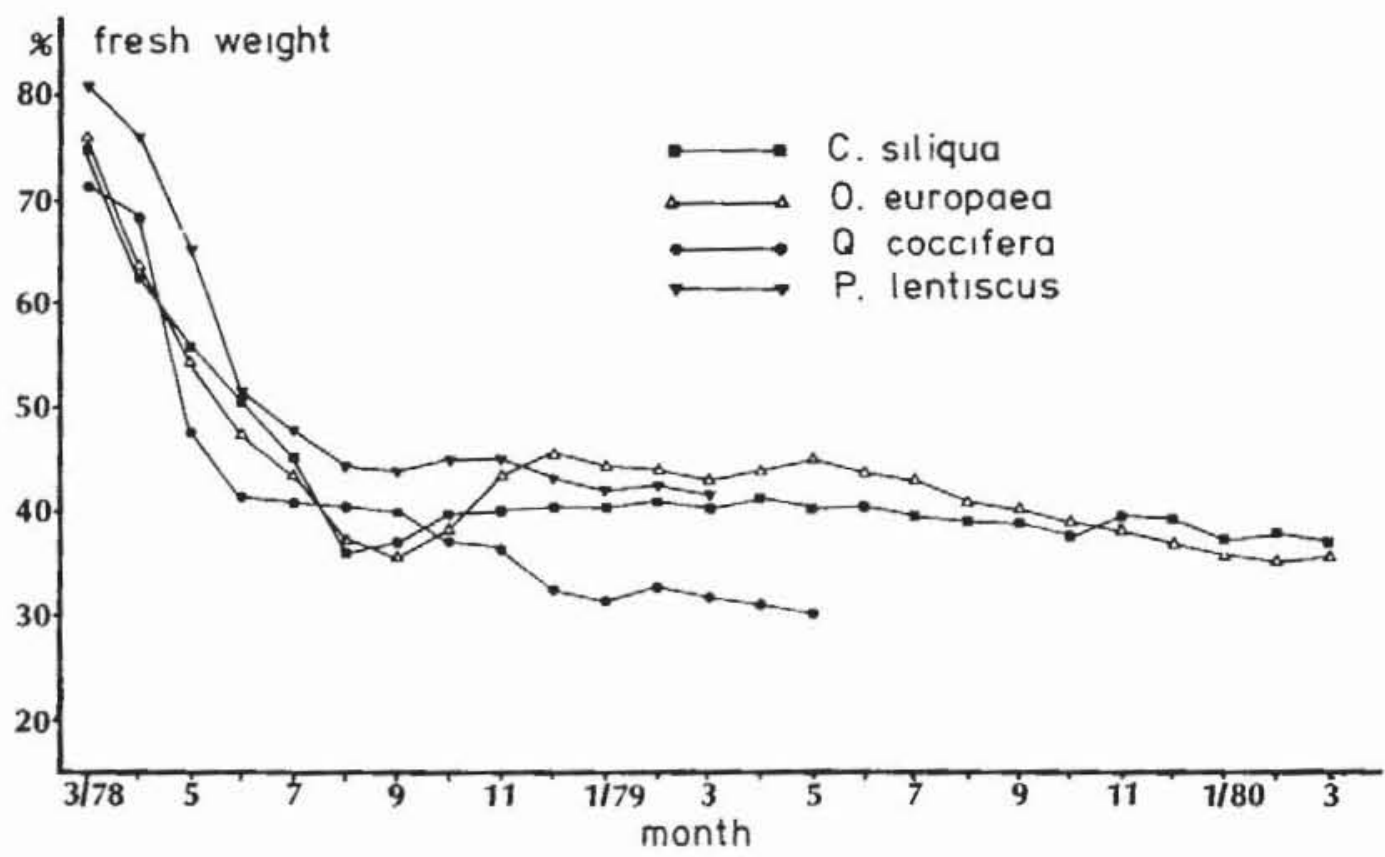

Abb. 2. Lebensdauer und Wassergehalte (in \% des Frischgewichts) der Blatter von Ceratonia, Olen, Quercus und Pistacia.

Fig. 2. Longevity and water content (as \% of fresh weight) of the leaves of Ceratonia, Olea, Quercus and Pistacia. 


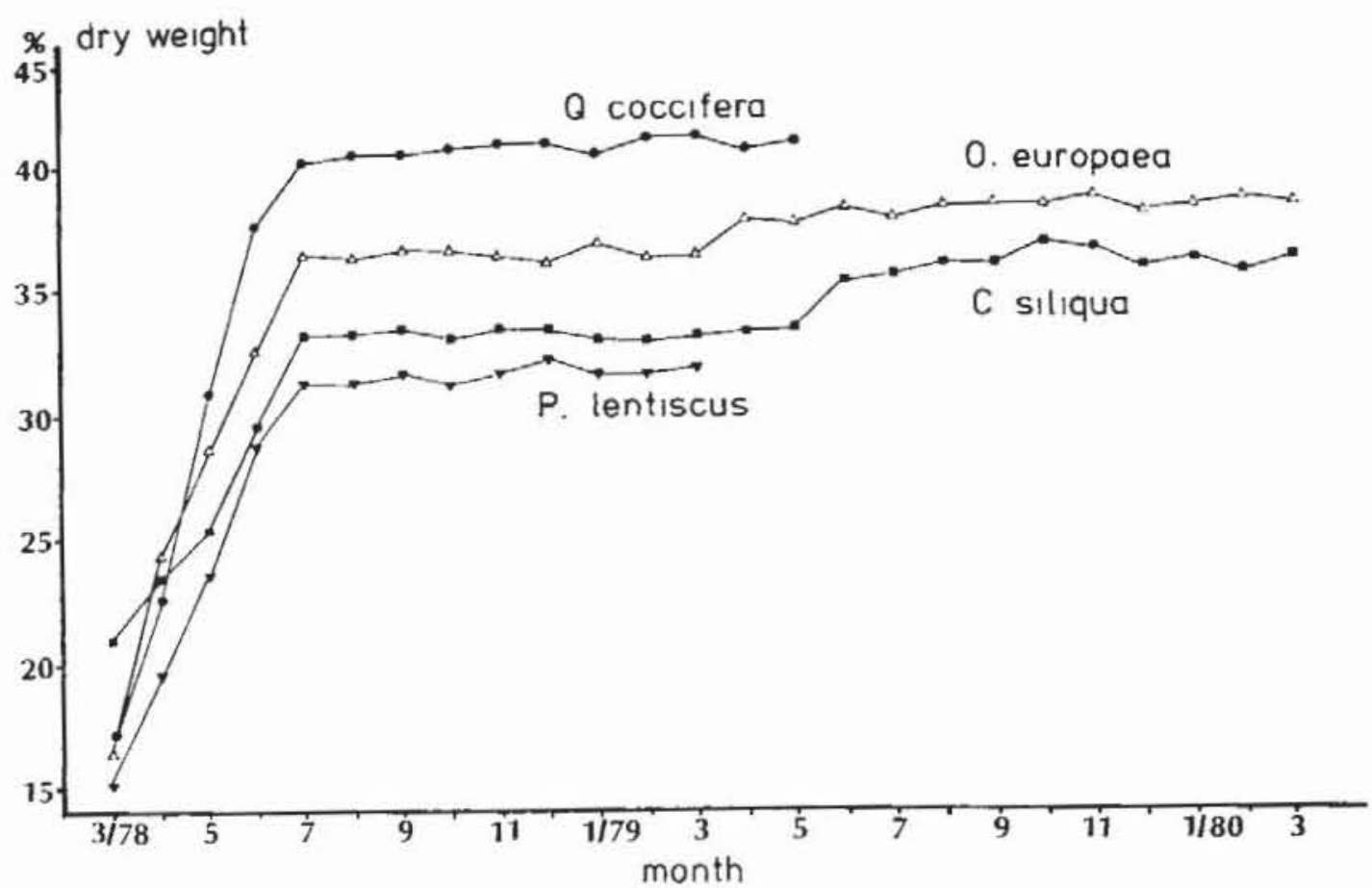

Abb. 3. a) Rohfusergehalte der Blatter von Cerrtonia, Olea, Quercus und Pistacia (in \%o der Trockenmasse).

Fig. 3. н) Kaw fibre content of the leaves of Cerrtonia, Olea, Quercus and Pistacia (as \% of dry weight).

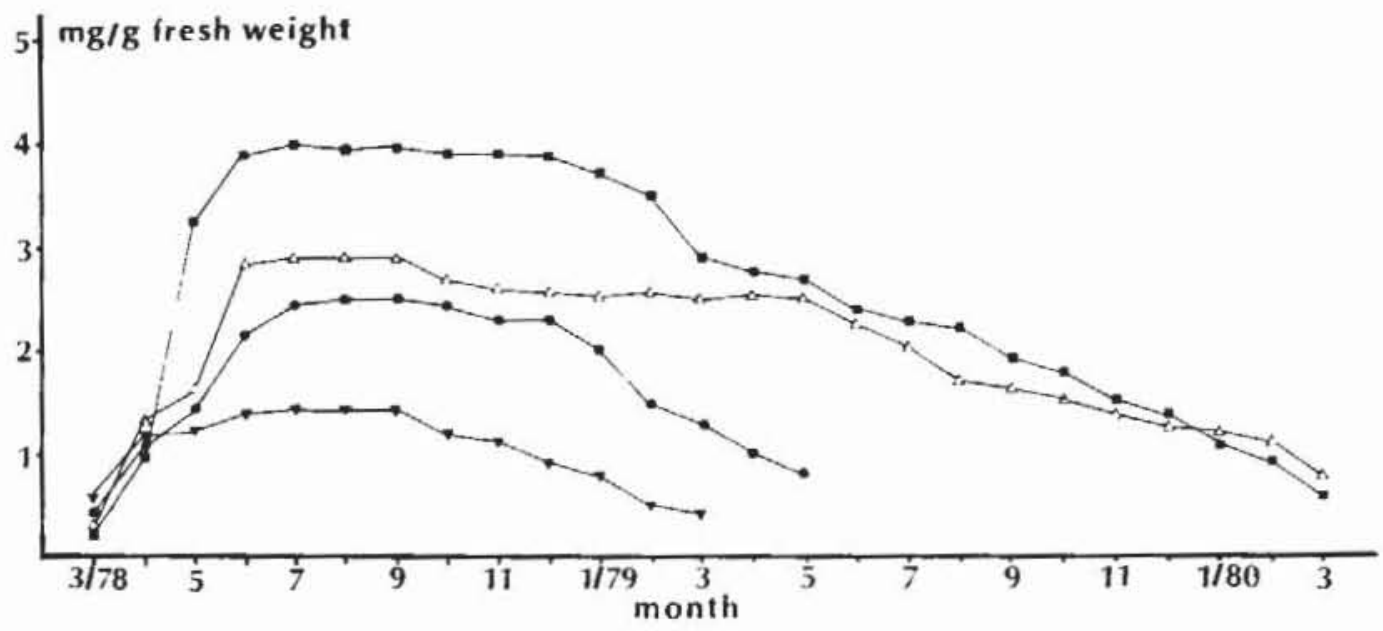

1bb. 3. b) Gesamtchlorophyllgehulte (mg/g Frischgewicht) der Blatter der 4 untersuchten Arten.

Fig. 3. b) Total (chlorophyll content (mg/g fresh weight) of the leaves of the 4 species investigated.

konstante Werte erreicht. Bei Quercus und Pistacia sinken die Werte wahrend der Wintermonate weiter. Bei Quercus coccifera enthalten die vergilbenden Blätter im Mai nu noch etwa $30^{\circ}$, Wasser. Bei Ceratonia und Olea, deren Blätter 2 Jahre leben, steigt der Wassergehalt zum Herbst/Winter hin an und sinkt dann ganz allmählich bis zum Blattfall.

\section{Rohfasergehalte}

C'm die Stickstoffgehalte zum Reifezustand der Blätter in Beziehung setzen zu komnen, wurden deren Rohfasergehalte bestimmt (Abb. 3a). Sie nehmen mit dem Heran wachsen der Blätter zunächst stark zu; bei allen 4 Arten ist der Wert der adulten Blatter im .Juli erreicht, wenn diese auch ihre endgültige Größe erreicht haben. Von 
diesem Zeitpunkt an treten bei Quercus und Pistacia keine Veránderungen mehr ein. Die beiden anderen Arten zeigen im Frühjahr des zweiten Jahres nochmals eine geringe Zunahme der Rohfasergehalte ihrer Blätter. Da ein Größenwachstum dieser Blätter nicht stattfindet, muß man annehmen, daß der Hartlaubcharakter (Xeromorphiegrad) aktiv verstärkt wird.

\section{C'hlorophyllgehalte}

Die Chlorophyllgehalte von Blättern stehen in enger Beziehung zum Stickstoffhaushalt, insbesondere zum Protein-Stickstoffgehalt (Мотнes 1931: MichaEL 1936; Zolg \& Bornkamm 1981: Freck et al. 1986 u. a.). Daher sind die ('hlorophyllgehalte auch wichtige Bezugsgrößen.

Wahrend der Blattentwicklung nehmen die Chlorophyllgehalte (Abb, 3b) bei allen 4 Arten zu und bleiben bei den ausgewachsenen Blättern ab Juni/Juli zunächst konstant. Bei Pistacia und Quercus nimmt die Chlorophyllmenge ab Herbst ab: bei den beiden anderen Arten beginnt im Frühjahr des zweiten Jahres eine kontinuierliche Abnahme lange vor einer erkennbaren Blattalterung. Die in den gealterten Blättern unmittelbar vor dem Absterben noch gefundenen Mengen liegen bei allen Arten in ahnlicher Höhe. Wahrend der Abnahme der Chlorophyllgehalte ist die Verringerung der Menge an Chlorophyll a stärker als jene von Chlorophyll b, so daß hei Ceratonia und Olea ungefähr ab September des zweiten Jahres der Chlorophyll-b-Anteil auf etwa $50 \%$ angestiegen ist und spater sogar überwiegt. Bei Quercus und Pislacia tritt dieser Effekt in den alternden Blättern ab Januar ein.

\section{Gesamt-Stickstoff}

Die auf die Trockenmasse bezogenen Gesamt-N-Gehalte (Abb. 4a) nehmen mit dem Blattwachstum ab. Bei Quercus coccifera setut das Blattwachstum friiher ein, daher erfolgt die Abnahme rascher. Etwa ab Juli bleiben die N-Gehalte zunachst konstant, da die Blatter nun ausgewachsen sind (vgl. Rohfasergehalte). Der N-(iehalt adulter Blätter gleichen Alters ist hei Ceratonia deutlich höher als bei den 3 anderen Arten. Bei den beiden Arten mit den kürzerlebigen Blattern setzt schon frih eine Abnahme der N-(iehalte ein: sie verläuft bei Pistacia rascher als bei Quercus. Bei Ceratonia hingegen findet im ersten Winter sogar eine N-Gehalts-Zunahme und erst ab dem zweiten Entwicklungsjahr der Blätter eine kontinuierliche Abnahme statt; die Abnahme verläuft bei Olea parallel. Beim Absterben der Blätter liegt der N-(iehalt in allen Fallen zwischen 4 und $6 \mathrm{mg} / \mathrm{g}$ Trockenmasse. Die Abnahme des N-(iehaltes vor dem Blattfall liegt bei Ceratonia und Pistacia bei ungefahr $60^{\circ}{ }_{0}$, bei Quercus betrágt sie etwa $55^{\circ}$ und bei Olea nur $45^{\circ}{ }_{0}$. Der Vorgang der Alterung ist an einer rascheren Abnahme der N-(xehalte in den letzten Lebensmonaten der Blätter außer bei Pistacia iberall deutlich zu erkennen. Bei Bezug der N-(iehalte auf die Rohfasermenge (Abb. 4h) erscheinen die Veränderungen ausgeglichener als bei der Bezugsgröße Trockenmasse; die Abweichungen bleiben aber gering. Bei den jungen Blattern wird die fortgesetzte Abnahme des N-(iehaltes deutlicher und im Anschluß an die Phase konstanter $\mathbf{N}$-(iehalte der Blätter ist die langanhaltende Abnahme der Stickstoffmenge gut zu erkennen.

\section{Protein-Stickst off und löslicher Stickst off}

Die Mengenveränderungen des Protein-Stickstoffs verlaufen bei allen 4 Arten weitgehend entsprechend jenen des (iesamt-N (Ahb. 5a). Man erkennt, daß die Zunahme des N-(xehaltes bei Ceratonin in den Wintermonaten auf den Anstieg der Proteinmenge zuriickgeht. 


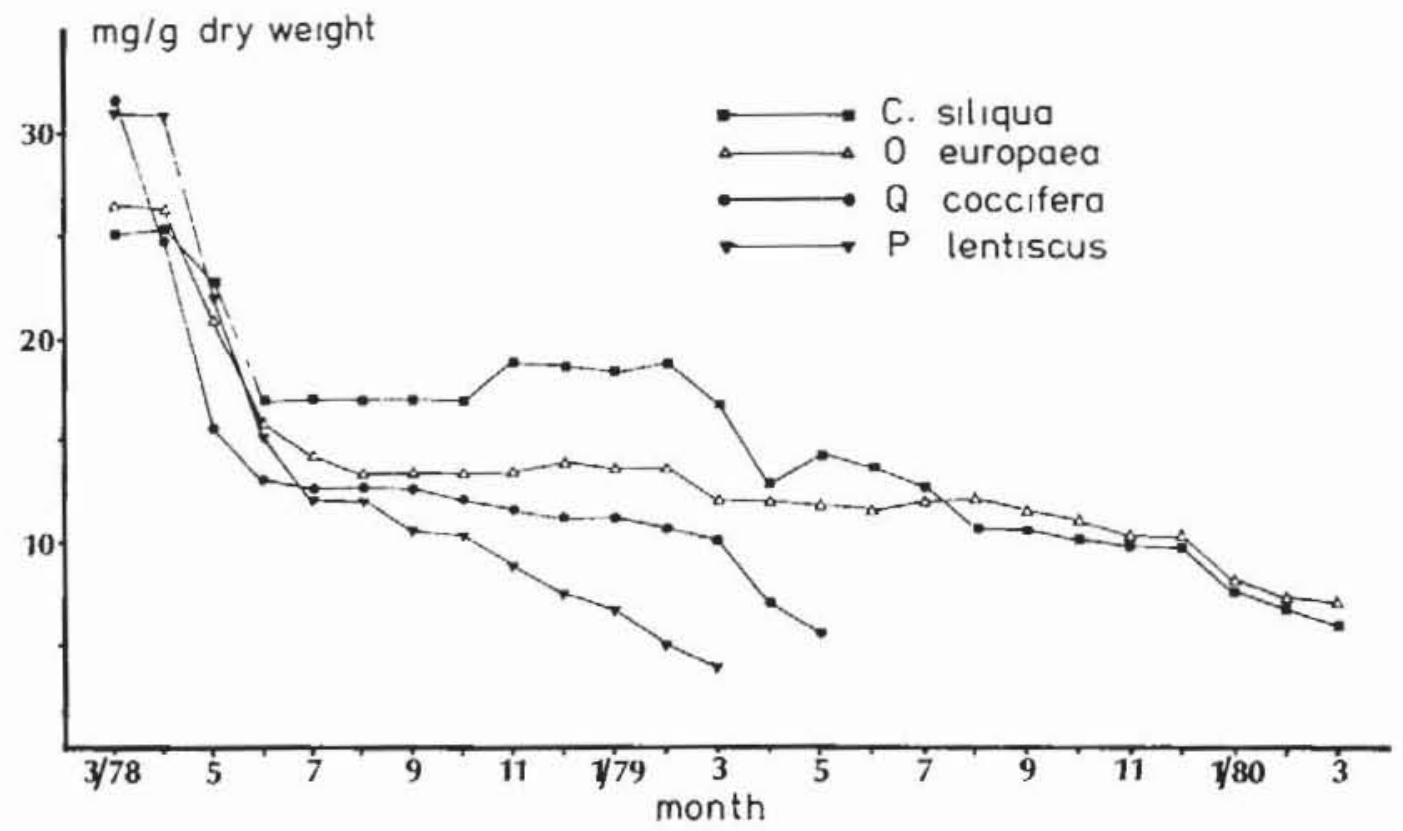

$4 a$

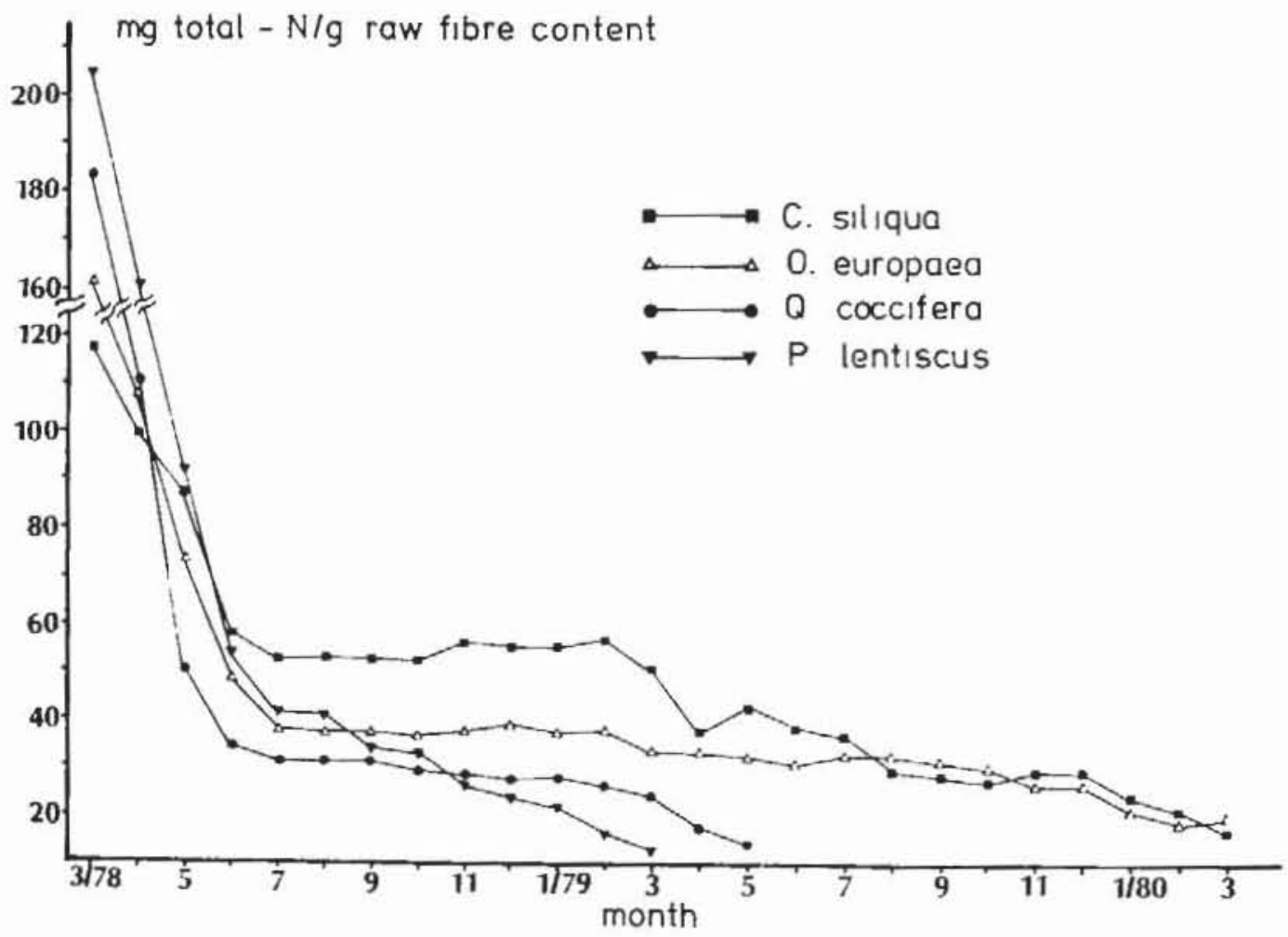

4b

Abb. 4. Gesumtstickst offgehalte der Blatter der 4 untersuchten Arten:

a) berogen auf die Trockennissse

b) berogen uuf den Rohfasergehalt

Fig. 4. Total $N$-content of the leaves of the 4 species investigated:

я) 4s $\mathrm{Hg} / \mathrm{g}$ dry weight

b) us mg/g ruw fibre content 


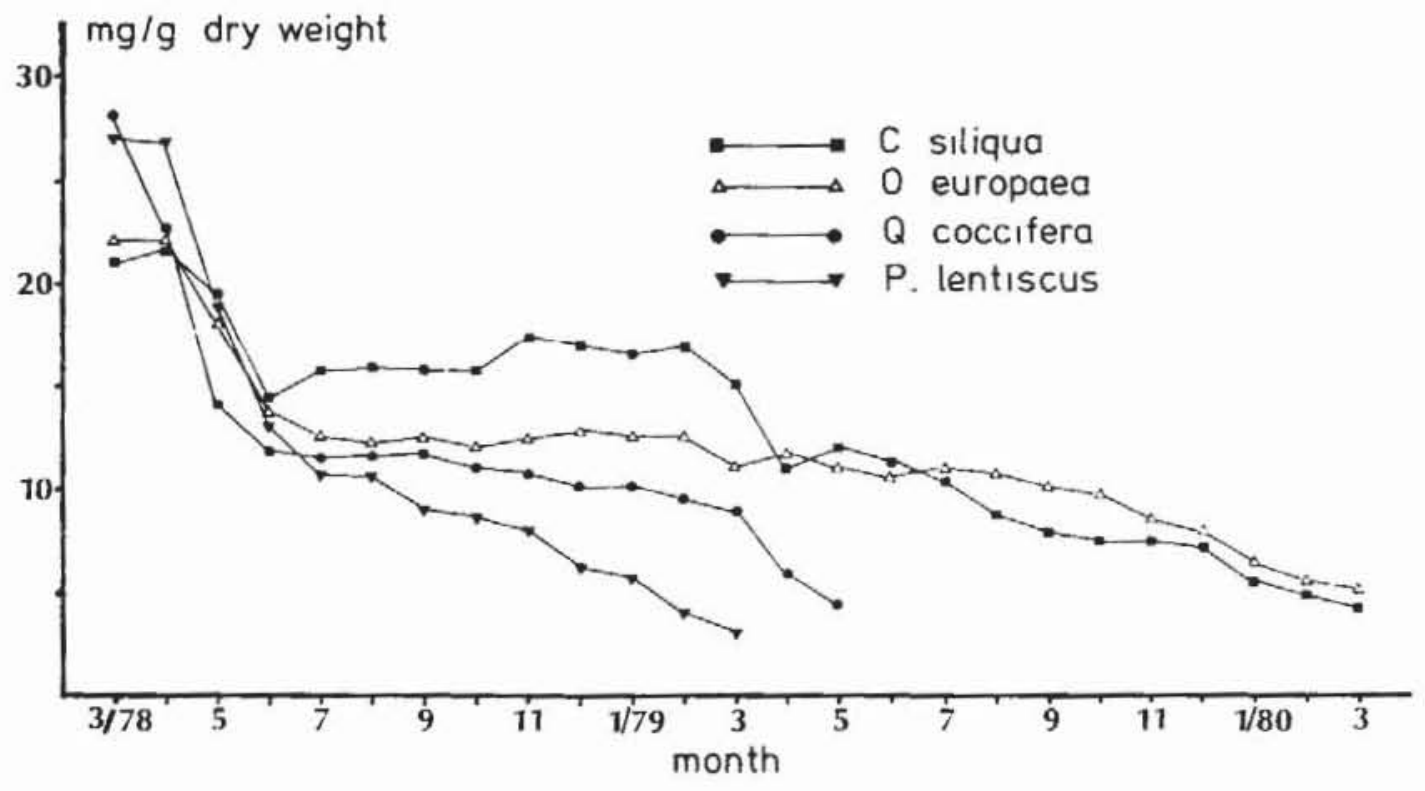

5 a

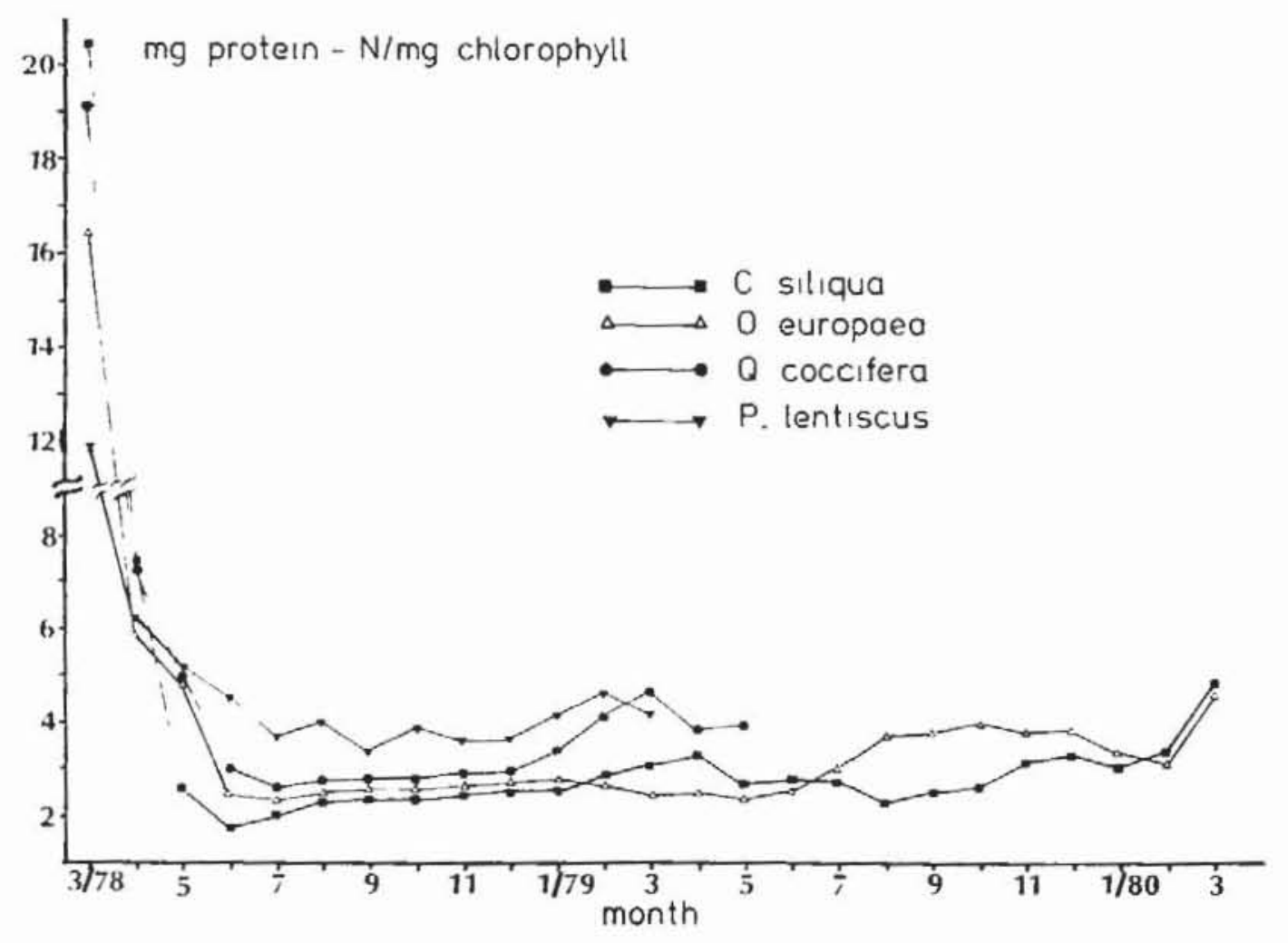

5b

Abb. 5. Protein-N-Gehalt der Blatter der 4 untersuchten Arten:

a) bezogen auf die Trockenmasse

b) bezogen auf den Chlorophyllgehalt

Fig. 5. Protein-N-content of the leaves of the 4 species investigated:

a) as nigig dry weight

b) us mg/ng chlorophyll 


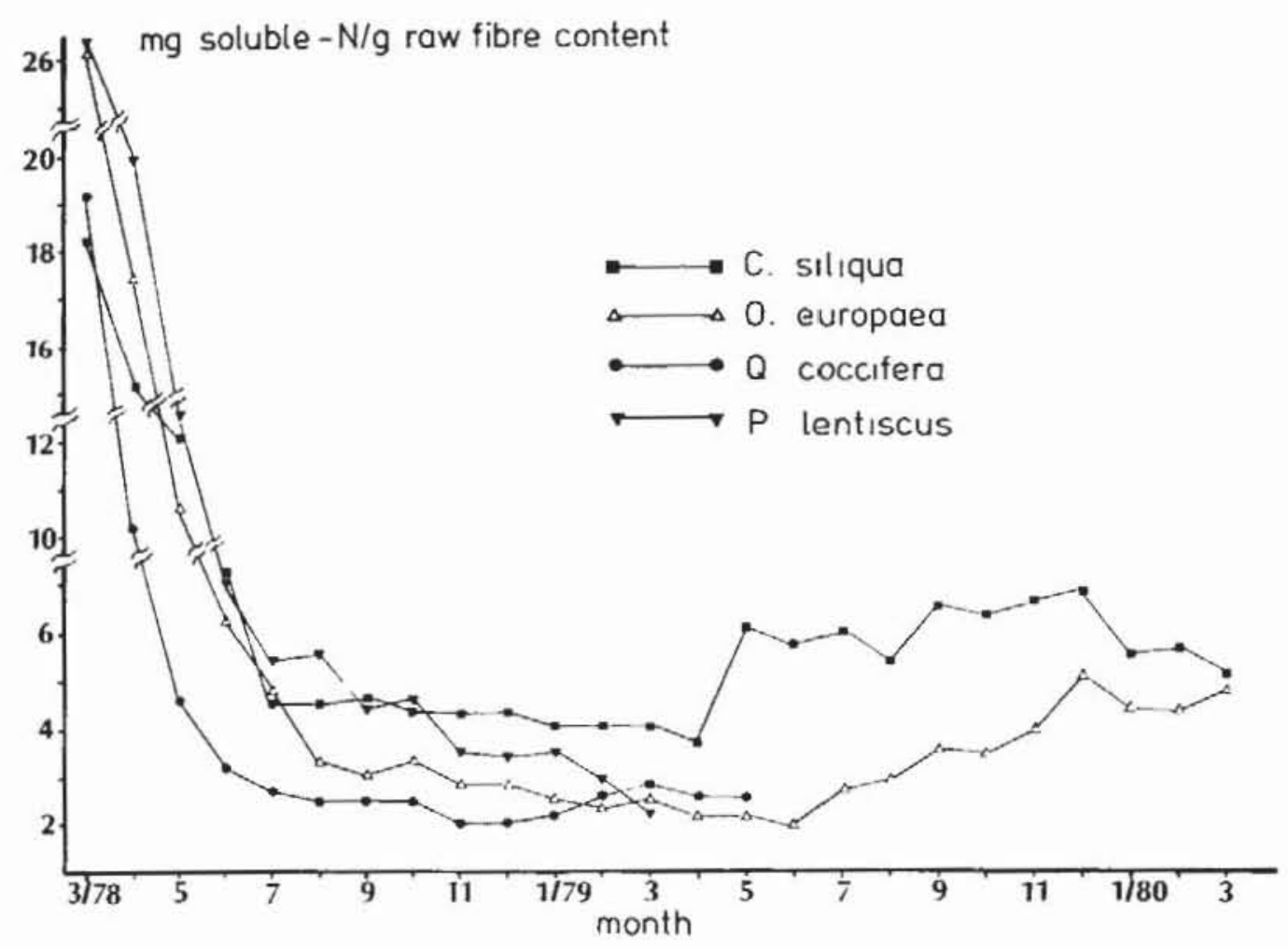

$6 \mathrm{a}$

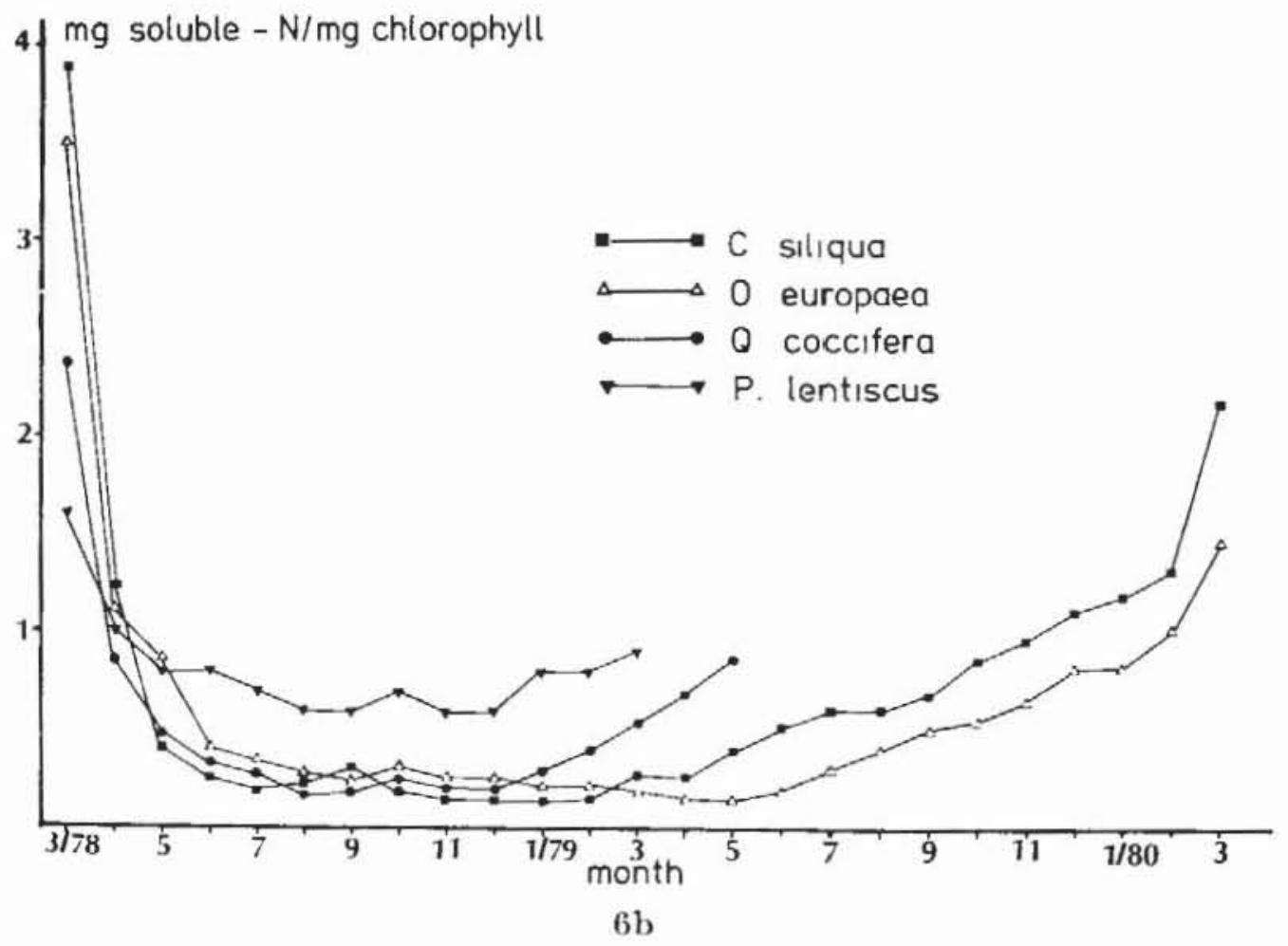

Abb. ti. Gehalt löslicher Stickst offverbindungen der Blatter der 4 untersuchten Arten:

a) bezogen uuf den Rohfasergehalt

b) bezogen uuf den Chlorophyllgehalt

Fig. 6. Soluble $\mathrm{X}$-content of the leaves of the 4 species investigated:

a) as mgimg raw fibre content

b) as mg'tug ('hlorophyll 
Die Proteingehalte (und ebenso die Mengen von (iesamt-N) bezogen auf die jeweiligen Chlorophyllgehalte nehmen mit dem Blattwachstum naturgemäß ab und bleiben bei ausgewachsenen Blättern zunächst konstant (Abb. כ̌b). Da ein (iroßteil der Proteine von Blattgeweben Chloroplastenproteine sind, ist ein solches Verhalten zu erwarten. Mit der Alterung der Blätter steigen die Werte an; der Abbau des Chlorophylls iiberwiegt also den Proteinabbau.

Die löslichen Stickstoffverbindungen haben nur einen relativ kleinen Anteil am $\mathrm{N}$-(iehalt. In wachsenden Blattern nehmen sie zunächst ab und zeigen dann kaum noch Veranderungen. Bei den 2 jährigen Blättern erfolgt eine Zunahme im zweiten Jahr, die bei Ceratonia auffälliger ist als bei Olea .

Bezieht man die Gehalte der löslichen N-Verbindungen auf den Rohfasergehalt, so werden ihre Veränderungen deutlicher (Abb. 6a). Die Zunahme im zweiten Entwicklungsjahr der Blätter setzt bei Ceratonia früher ein als bei Olea und hat offenbar keine unmittelbaren Beziehungen zur Alterung. Die frühe Zunahme bei Ceratonia im April/Mai macht auch eine Beziehung zur Dürreresistenz unwahrscheinlich. In den letzten Lebensmonaten der Blätter nimmt bei Ceratonia und Pistacia mit der Alterung der Gehalt löslicher N-Verbindungen wieder ab. Bei Quercus ist dieser Effekt nur gering ausgeprägt und bei Olea fehlt er völlig, so daß hier die $N$-Abnahme während der Seneszenz allein auf das Verhalten des Protein-Stickstoffs zurückzufïhren ist.

Bezieht man die ('ehalte löslichen Stickst offs a uf die Chlorophyllgehalte (Abb. 6b), so wird wiederum der frih einsetzende Chlorophyllabbau erkennbar; die löslichen $\hat{N}$-Verbindungen nehmen - relativ gesehen - allmählich und in der Endphase der Alterung der 2jährigen Blätter rasch zu. Vor dem Einsetzen der Alterungsvorgánge ist der Anteil löslichen Stickstoffs bezogen auf den Chlorophyllgehalt bei Ceratonia, Olea und Quercus nahezu gleich und liegt bei ca. $0,4 \mathrm{mg} / \mathrm{mg}$ Chlorophyll; bei Pistacia hingegen ist der Wert ungefähr doppelt so hoch.

Cnter den löslichen N-Verbindungen ist Prolin als Streßmetabolit von Bedeutung. Daher wurden die Prolingehalte der Blätter im Winter (Ernte: Januar 1986: Kältestreß) und im Sommer (Ernte: Ende August 1985; Dïrrestreß) bestimmt (Abb. 7). Stets ist die Prolinmenge bei Durrebelastung höher als in den Wintermonaten, die allerdings keine ausgeprägte und fur mediterrane Arten möglicherweise kritische Kaltezeit aufwiesen. Die sommerliche Prolin-Akkumulation ist bei Olea und Ceratonia viel stärker als bei den Arten mit den kürzerlebigen Blattern, unter denen Quercus

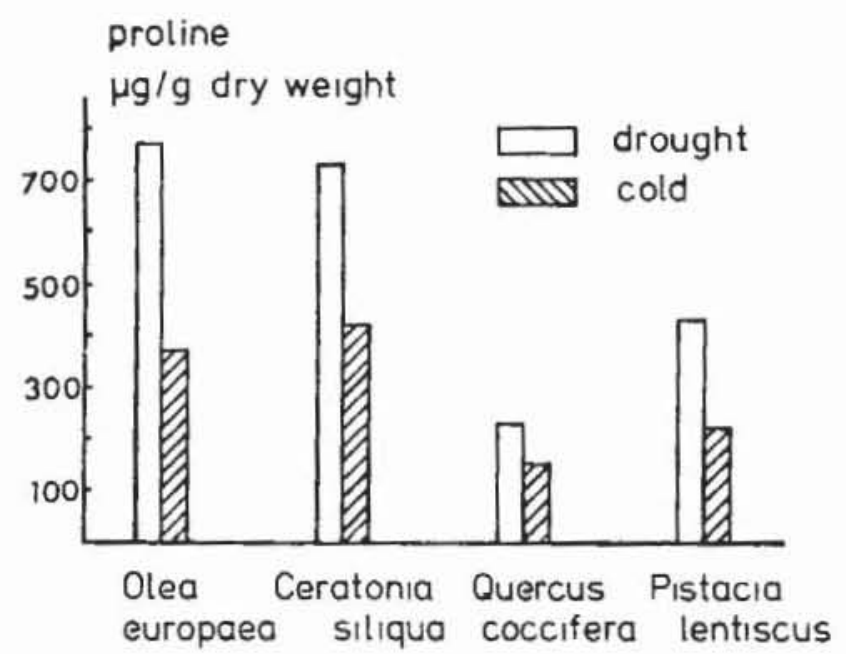

Abb. 7. Prolingehalte (in $\mu$ g Prolin/g Trockenmasse) der Blatter der 4 Arten unter nutiurlichen Bedingungen von Dürre (Ende August) und von Kalte (Junuar).

Fig. 7. Prolin content ( $\mu \mathrm{g}$ prolin/g dry weight) of the leaves of the 4 species under nutural conditions of drought (end of August) and of cold (January). 
Tabelle 1. Ionengehalte der Böden der Standorte von Ceratonia (a) und von Olea, Quercus und Pistacia (b), bezogen auf die Trockenmasse

\begin{tabular}{|c|c|c|c|c|c|c|}
\hline & \multicolumn{4}{|l|}{ o } & \multicolumn{2}{|l|}{$\mathrm{ppm}$} \\
\hline & $\mathrm{Na}$ & $\mathrm{K}-$ & $\mathrm{Ca}^{2}-$ & $\mathrm{Mg}^{2-}$ & $\mathrm{NO}_{3}^{-}$ & $\mathrm{PO}_{4}{ }^{3-}$ \\
\hline a & 0,01 & 0,07 & 8,5 & 0,97 & 0,6 & 21 \\
\hline b & 0,01 & 0,23 & 0,96 & $0,3 \breve{s}$ & 1,1 & 17 \\
\hline
\end{tabular}

coccifera die geringsten Prolingehalte und auch deren sch wächsten Anstieg vom Winter zum Sommer zeigte.

\section{Ionengehalte der Böden}

Böden des Standortes von Ceratonia einerseits und der 3 weiteren Arten andererseits wurden auf die wichtigsten Ionen untersucht (Tabelle 1). Die Böden wurden im Marz 1984 entnommen, bei $100^{\circ} \mathrm{C}$ getrocknet und dann bis zur Lntersuchung in verschlossenen Plastiktiiten aufbewahrt. Zur Beurteilung der Werte ist der Hinweis wichtig, da $\beta$ die Bestimmung der Kationen aus dem Gesamtaufschluß und nicht aus dem Lactatauszug erfolgte. Der Standort von Ceratonia zeigt einen deutlich höheren Kalkgehalt. Die jahreszeitlich erheblichen Schwankungen der Ionengehalte, insbesondere der Nitratgehalte, werden durch eine derartige Stichprobe natirlich nicht erfaßt.

\section{Diskussion}

Bei der Entwicklung der jungen Blätter verändern sich natürlich alle untersuchten (irößen stark. Der Stickstoffgehalt nimmt infolge des Blattwachstums allein schon durch einen Verdïnnungseffekt infolge der starken Biomassenzunahme ab. Ein Vergleich der verschiedenen gemessenen Größen zeigt, daß zuerst ein konstanter C'hlorophyllgehalt erreicht wird. Dann erfolgt der AbschluB des Flächenwachstums und die Rohfasermenge wird konstant; die Blatter sind nummehr ausgewachsen. Et wa gleichzeitig oder spater wird ein konstanter Stickstoffgehalt erreicht und außer bei Quercus coccifera schließt das Einpendeln auf einen weitgehend konstanten Blattwassergehalt die Entwicklungsvorgange ab. Die Abnahme des löslichen Stickstoffs während der Entwicklung der Blätter, die von vielen Arten bekannt ist (EDER \& Kixzel 1983, dort weitere Lit.), kann nach den Befunden dieser Autoren nicht allein auf den erwahnten Verdünnungseffekt zurïckgeführt werden.

In den adulten Blattern bleibt für lange Zeit die auf den Chlorophyllgehalt bezogene Menge des Protein-Stickstoffs konstant: dies ist verständlich, da die Chloroplastenproteine den größten Anteil an den Blattproteinen haben. Beginnende Alterungsvorgänge werden fris durch die Abnahme der Chlorophyllgehalte und die Zunahme des löslichen Stickstoffs angezeigt: letztere ist besonders deutlich bei Bezug auf den Rohfasergehalt oder den Chlorophyllgehalt zu erkennen. Dies entspricht Befunden von Specht-Jürgensen (1967) und Côté \& Dawson (1986). Die Veränderungen der (iesamtchlorophyllmengen sind - abgesehen vom langsameren Verlauf jenen bei sommergrïnen Arten (KRIEBITzsch 1984) vergleichbar. Ein verstärkter Abhan von ('hlorophyll a gegenüber Chlorophyll b bei der Blattalterung wurde auch von ZoLG \& BorNKamm (1981) beschrieben. Die frïh einsetzende Abnahme der ('hlorophyllgehalte bei unseren Untersuchungsobjekten ist sehr auffällig: da sie bei allen 4 Arten zu beobachten ist, könnte sie für Hartlaubarten charakteristisch sein.

Die allmähliche Abnahme des Protein-Stickstoffs durch Proteinabbau und des (iesamt-Stickst offgehalts infolge des Stickstoff-Exports, der sich gegen Ende der 
Lebenszeit der Blätter noch verstärkt, sind von krautigen Arten und sommergrïnen Báumen lange bekannt (Mothes 1931: Deleano \& ANdreEsco 1932: ('ÄLmaNN 1935: Нichael 1936: Zolg \& Bornkamm 1981; Eder \& Kinzel 1983, dort weitere Lit.) und neuerdings auch für kretische Dornpolsterpflanzen nachgewiesen (HönER \& Breckle 1986). Die Hartlaubblätter sind nach Einsetzen der Stickstoffabnahme noch lange Zeit physiologisch aktiv, wie auch ihr Speicherverhalten erkennen laßt (vgl. Diamantoglou \& Kill, 1982). Die endgiiltige Alterung mit nachfolgendem Blattfall erfolgt ïberwiegend in der Hauptwachstumsphase; dies gilt auch für vorzeitig alternde Blätter (Diamantoglot \& Mitrakos, 1981). Die alternden Blätter dienen als Stickstofflieferanten für die wachsenden Gewebe.

Die zeitlichen Veränderungen der Gesamt-Stickstoffgehalte sind weitgehend durch das Verhalten des Protein-Stickstoffs bestimmt. Sie entsprechen den Befunden bei Immergrïnen des kalifornischen Chaparral (Moovey \& RtNDel 1979; Merino et al. 1984) und anderer Klimate (Woodwell 1974; Tirner \& Olson 1976; Chapin \& Kenrowski 1983). Bei Citrus findet man hingegen Abweichungen (Moreno \& (raRcla-Martinez 1984). Die absoluten N-(iehalte der Blatter der mediterranen Hartlaubarten sind geringer als bei sommergrünen Arten, zeigen aber ähnliche Werte wie bei den Chaparral-Arten und auch wie bei Immergrünen in Mitteleuropa (z. B. Stöcker 1976: Distelbarth et al. 1984). Mit den stichprobenhaften Daten aus (iriechenland von Margaris et al. (1981) stehen unsere Werte ebenfalls in Einklang. Sklerophylle Blätter weisen eine geringere Photosyntheseleistung auf als malakophylle (Larcher 1984). Cm gleiche Effizienz der Stickstoff-Nutzung zu erreichen, müssen sie daher deutlich länger leben. Dies wiederum fördert die Xeromorphie. Mit dieser Čberlegung steht in Einklang, daß die N-(iehalte bei Bezug auf den Rohfasergehalt (der als Maß für die Yeromorphie gelten kann) geringere Unterschiede zwischen den untersuchten Arten aufweisen, als bei Bezug auf die Trockenmasse; vor allem zwischen Pistacia und Quercus (mit dentlich verschiedenen Rohfasergehalten) verschwinden die Differenzen. Die Kosten/Nutzen- ${ }^{t}$ herlegung zeigt ferner, daß der Stickstoffgehalt bei längerlebigen Blattern unter sonst identischen Bedingungen höher sein kann als bei kürzerlebigen Blättern (Снавот \& Hгскs 1982). Tatsächlich sind die N-Gehalte der Blatter von Ceratonia und Olea höher als jene von Quercus und Pistacia. Die Stickstoffgehalte von Ceratonia-Blattern sind höher als in den meisten Immergrinen. Dies dïrfte mit der Rhizobium-Symbiose dieser Leguminose zusammenhangen. Die hohen $\mathrm{N}$-Gehalte werfen die Frage auf, welche wirksamen FraBschutzmechanismen Ceratonia besitzt.

Wenn für die von uns untersuchten mediterranen Arten ahnliche Beziehungen zutreffen, wie sie FIELD et al. (1983) bei kalifornischen Immergriinen fanden, so ist bei besonders gut an die Trockenheit adaptierten Arten das Verhältnis von Photosynthese-Leistung zu Blatt-N-(iehalt niedrig. Der hohe N-Gehalt der Blätter von Ceratonia wäre also mit einer höheren Photosynthese-Leistung korreliert, womit die hohe Diirreresistenz dieser Art zusammenhängen könnte. Blatter mit einer 2- oder mehrjahrigen Lebensdauer können auch als N-Speicher während der Wintermonate dienen (Chapis \& Kedrowski 1983). Dies ist bei Ceratonia deutlich zu erkennen. (ileichartige Befunde gibt es von Moover \& Rundel (1979) an Adenostoma aus Kalifornien; als Crsache wurde eine verstärkte $\mathrm{N}$-Aufnahme in der kühleren und gleichzeitig feuchten Jahreszeit festgestellt. Die Verlagerung von Stickstoff im Friihjahr des zweiten Jahres in wachsende Gewebe lange vor einer Alterung der Blätter entspricht den Modellïberlegungen von STöcker (1980).

Das Ausmaß des Stickstoff-Exports bei der Alterung liegt in ahnlicher Höhe wie bei anderen Immergrïnen (vgl. CHAPIs \& KEvRowski 1983, dort weitere Lit.). Gcluox (1983) gibt an, daß maximal $60^{\circ}$, des Blatt-Stickstoffs abtransportiert werden: dies entspricht ziemlich genau den höchsten von uns an Ceratonia und 
Pistacia gemessenen Werten. Infolge der Zunahme des löslichen Stickstoffs bei der Alterung sollte der im Bestandesabfall verbleibende Stickstoff für die Destruenten relativ rasch verfügbar sein; dem steht aber der Hartlaubcharakter der Blätter partiell entgegen.

Die Abnahme des Proteingehalts der Blätter verringert den Energieaufwand für deren Erhaltung (MErino et al. 1984). Ein zum Herbst/Winter hin ansteigender Lipidgehalt (vgl. Diamantoglor \& Krul, 1982) läßt den Erhaltungsaufwand aber wieder ansteigen, wie die Cntersuchungen von MERINo et al. an der immergriinen Chaparral-Pflanze Heteromeles zeigen. Allerdings zeigen die Speicherlipide zumindest teilweise bekanntlich nur einen geringen Umsatz, so daß der Anstieg der Erhaltungskosten von MERINo et al. möglicherweise zu hoch angesetzt worden ist.

Die Sommertrockenheit wirkt sich auf den Stickstoffhaushalt nur wenig aus. Möglicherweise ist die $\mathrm{N}$-Aufnahme gehemmt; inwieweit eine Verringerung disponiblen Stickstoffs auf die Erhöhung der Diirreresistenz Einfluß nimmt (RADIN \& PARKer 1979), bleibt offen. In C̈bereinstimmung mit den Befunden dieser Autoren ist festzustellen, daß die Osmoregulation durch den N-Stat us offensichtlich nicht beeinflußt wird. Der osmotischen Adaptation dient Prolin, dessen Rolle als StreßMetabolit gut bekannt ist (Zusammenfassungen bei STEwarT \& Larher 1980; BradFord \& Hsiao 1982). Prolin wird in allen 4 Arten während der sommerlichen Trockenheit viel starker akkumuliert als bei Kälte. Bei Quercus und Pistıciı, die sommers weniger Prolin enthalten als Olea und Ceratonia, werden auch die Zucker in dieser Zeit vermehrt. Bei Ceratonia hingegen kommt es nicht zu einer Zuckeranhäufung in den Sommermonaten (Diamantoglot: \& Meletioi-Christou 1978, 1980). Bei Quercus mit der geringsten Prolin-Akkumulation ist der Xeromorphiegrad der Blätter am höchsten. Die Prolin-Akkumulation deutet darauf hin, daß der wirksamste Streßfaktor für die Hartlaubarten an ihrem natïrlichen Standort bei Athen die Dürre ist und nicht die kühle Jahreszeit mit ihren nur wenigen Frosttagen. Dies bestatigt und ergänzt unsere früheren Schlußfolgerungen (DIaMANTogroc \& KLLL 1982). Bei Citrus, einer ('attung, die nicht aus einem mediterranen Klimagebiet stammt, wird der Prolingehalt hingegen sowohl bei Dürre als auch bei niedrigen Temperaturen stark erhöht (Syvertsen \& Smith 1983; Moreno \& Garcia-Martinez 1984).

Die Messungen von Ionengehalten der Böden ergaben für Nitrat und Phosphat Werte, die mit den Messungen von Leclerc (1985) an mediterranen Sandböden vergleichbar sind. Der geringe Nitratgehalt entspricht jenem vieler Böden, die arm an mineralischem Stickst off sind. Der geringe Nitratgehalt der Böden sollte dazu führen, da $B$ die Nit ratassimilation ausschließlich in der Wurzel der Pflanzen erfolgt (ANDREws 1986). Fur die N-Versorgung der Pflanzen liefern allerdings als Stichproben gemessene Tiehalte eines Bodens an Nitrat, Ammonium oder Gesamtstickstoff kein geeignetes Maß. Daher hatten auch mehrere Messungen im .Jahresverlauf keine weitergehenden Aussagen ermöglicht, so daß darauf verzichtet wurde.

\section{Dank}

Unser Dank gilt der VW-Stiftung fur finanzielle Unterstutzung in Rahmen eines Purtnerschuftsvorhabens. Fur die sorgfaltige Durchfuhrung von Messungen haben wir Frau ELENI BaKopol lov und Frau Georgia Siapsali, fü die Durchfühung der AAS-Messungen Herrn Dr. M. Hol.zwarth (1)armistadt) $\%$ danken. Für wertvolle Hinweise zur Nitrat- und Phosphathestimmung danken wir Herrn Prof. Dr. E. SсндіснтікG, Univ. Hohenheim. 


\section{Literatur}

Andrews, M. (1986): The partitioning of nitrate assimilation between root and shoot of higher plants. Plant Cell Environm. 9: $511-519$.

Bates, L. S., Waldrex, R. P., \& Teare, I. D. (1973): Rapid determination of free proline for water-stress studies. Plant and Soil 39: 205-207.

BRADFOKD, K. J., \& HsiaO, T. C. (1982): Physiological responses to moderate water stress. In: Lavge, O. L., Nobel, P. S., Oswond, C. B., \& Ziegler, H. (eds.): Encyclopedia Plant Physiology, X. S. 12 B. Berlin. $264-324$.

('навот, B. F., \& Hicks, D. J. (1982): The ecology of leaf life spans. Ann. Rev. Ecol. Syst. 13: $229-259$.

Chapin, F. St., \& Kedrowsi, R. A. (1983): Seasonal changes in nitrogen and phosphorus fractions and a utumn retranslocation in evergreen and deciduous triga trees. Ecology $64: 376-391$.

Ć́t́́, B., \& Dawson, J. O. (1986): Autumnal changes in total nitrogen, salt-extractable proteins and anino acids in leaves and adjacent bark of black alder, eastern cottonwood rnd white basswood. Physiol. plant. 67: 102-108.

Deiefno, X. T., \& Axdreesco, M. I. (1932): Beitrage zum Studium der Rolle und Wirkungsweise der Mineral- und orgunischen Stoffe im Pflanzenleben. 1. Mitt.: Der quantitative Stoffwechsel der Mineral- und organischen Substanzen in den Salıx fragilis-Blättern wahrend ihrer Entwicklung. Beitr. Biol. Pflanzen 19: 249-286.

Diamantogloc, S., \& KLLt, U. (1982): Die Jahresperiodik der Fettspeicherung und ihre Beziehungen zum Kohlenhydrathaushalt bei inmergrunen mediterranen Holzpflanzen. Acta Oecol./Oecol. Plant. 3: 231-248.

- \& Meletiov-Christoc, M.S. (1978): Kohlenhydratgehalte und osmotische Verhaltnisse bei Blattern und Rinden von Ceratonia siliqua und Quercus coccifera im Jahresgang. Flora 167: $472-479$.

- - (1980): Kohlenhydratgehalte und osmotische Verhailtnisse bei Blattern und Rinden von Pistrcin lentiscus, Pistacia terebinthus und Pistacin vera in Jahresgang. Flora 169: 168-176.

- \& Mrтакоs, K. (1981): Leaf longevity in mediterranean evergreen sclerophylls. In: MarGARIS, N.S., \& MOONEY, H. A. (eds.): Components of productivity of mediterreanean climate regions. The Hague. 17-19.

Distelbarth, H., K'Ll, U., \& Jeremas, K. (1984): Seasonal trends in evergreen gymnospermis growing under mild climatic conditions in Central Europe. Flora 175: 15-30.

Ener, M., \& Kinzer, H. (1983): Seasonal variations in free amino acid contents of deciduous Ericricene leaves. Z. Pflanzenphysiol. 112: 269-273.

Fiem.d, C., Meriso, S., \& Mooney, H. A. (1983): Compromises between water-use efficiency and nitrogen-use efficiency in five species of California evergreens. Oecologia 60: $384-389$.

Fleck, I., Fransi, A., \& VidAL, D. (1986): Senescence patterns of severul physiological and biochemical parameters of field grown flag leaves of Triticum nestivum L. ev. Kolibri. J. Plant Physiol. 123: 327-338.

G.̈̈manv, E. (1935): Der Stoffhaushalt der Buche (Fagus sylvatica L.) im Laufe eines Juhres. Ber. Schweiz. Bot. Ges. 44: $157-334$.

GrLmox, S. L. (1983): Carbon and nitrogen economy of Diplacus uurantiacus; a Californian mediterranean-climate drought-deciduous shrub. In: Krtger, F. J., Mitchel., D. T., \& JARvis, J. U. M. (eds.). Mediterranean-Type Ecosystems - The Role of Nutrients. Ecol. Studies 43: Berlin. 167-176.

Hōlr.warte, M. (1976): Der Stickstoffhaushalt von Pappelrinden und seine Beziehungen zur Temperatur. Z. Pflanzenphysiol. 80: 215-224.

Hóner, D., \& BREckite, S.-W. (1986): Untersuchungen zum Speicherstoff-Gehalt der Dornpolster in den Hochgebirgslagen Kretas (Griechenlund). Flora 178: 297-305.

KJeldahl, J. (1883): C ber die Stickstoffbestimmung. Z. Analyt. Chem. 22: 366-370.

Kriebitzsch, W.-U. (1984): Jahresgang des Chlorophyllgehaltes in den Blattern von Mercurialis perennis L. Flora 175: 111-115.

LARCher, W. (1984): Okologie der Pflanzen. 4. Aufl. Stuttgart.

LECr.ERC, M.-CL. (1985): Variations saisonnières de la disponibilité du nitrate et de son utilisation pa lu végétation des dunes littorales del a Méditerranée. Acta Oecol./Oecol. Plant. 6: 87-106. 
Margaris, X.S., Anamanuador, S., SiafaCa, L., \& Diamastopot los, J. (1944): Nitrogen and phosphorus content in plant species of Mediterruneun ecosystems in Greece. Vegetatio 55: $29-35$.

Merino, J., Field, C'., \& Moovex, H. A. (1984): ('onstruction and maintenunce costs of mediterranean-clinute evergreen and deciduous leaves. II Biochemical pathway analysis. Acta Oecol./Oecol. Plant. 5: $211-229$.

Мснавц, G. (1936): L'ber die Beziehungen zwischen ('hlorophyll- und Eiweißabbau in vergilbenden Laubblatt von Tropaeolum. Z. Bot. $29: 3 \times 5-425$.

Mooxey, H. A., \& Rixnes, P. W. (1979): Nutrient relations of the evergreen shrub, Adenostoma fasciculatum, in the Californin chaparral. Bot. Gaz. $140: 109-113$.

Moreno, J., \& Garcia-Martinez, J. L. (19x4): Nitrogen recunulation and mobilization in Citrus leaves throughout the annual cycle. Physiol. plunt. 61: 429-434.

Moтнes, K. (1931): Zur Kenntnis des X-Stoffwechsels höherer Pflanzen. 3. Beitrag (Unter besonderer Beriacksichtigung des Blattalters und des Wusserhaushaltes). Planta 12: 6isti-731.

RADIN, J. W., \& PARkER, L. L. (1979): Water relations of cotton plants under nitrogen deficiency. I 1)ependence upon leaf structure. Plant Physiol. 64: 495-498.

śchlichting, E., \& Bixмe, H. P. (1966): Bodenkundliches Praktikum. P. Parey, Hanburg.

SPECHT-JTRGENSEs, I. (1967): Untersuchungen uber Stickstoffverbindungen und Chlorophyll wahrend des Vergilbens der Luubblatter von Ginkgo biloba. Floru A I57: 426-453.

Stetbixg, L. (1965): Pflanzenokologisches Praktikum. P. Parey, Hamburg.

STEWART, G. R., \& LARHER, F. (1980): Accumulation of amino acids and related compounds in relution to environmental stress. In: S'Tumf, P.K. (ed.): The Biochemistry of Plants. Vol. 5, Sew York. 609-635.

ŚтоскER, G. (1976): Untersuchungen uber Stickstoff-Blattspiegelwerte einiger Bodenpflanzen naturnaher Berg-Fichtenwalder. Flora 165: 457-47 .

- (198(1): Ökologische Aspekte der saisonulen Veranderung von Stickstoff-Blattspiegelwerten. Flora 170: $316-32 \%$.

Sirvertsen, J. P., \& SMith, M. L. (19s3): Environmental stress and seasonal changes in proline concentrution of Catrus tree tissues and juice. J. Aner. Soc. Hort. Sci. 108: 861 -866.

Thomas, H., \& Stomdart, L. J. (1980): Leaf senescence. Ann. Rev. Plint Physiol. 31: 83--111.

Trener, J., \& Olsox, P. R. (1976): Nitrogen relations in y Douglas-fir plantation. Ann. Bot., ‥ S., 40: $1185-1193$.

Woonwer., G. M. (1974): Vuriations in the nutrient content of leaves of Quercus albu, Quercus coccinen, and Pinus rigidn in the Brookhrven forest from bud-break to abscission. Aner. J. Bot. 61: $749-753$.

Zotf, M., \& Borskam, R. (1981): Analytische Untersuchung an Blattern wahrend iles Alterungsprozesses vor dem Luubfall. Floru 171 : $355-36$ - 36 .

Eingegungen am 17. Februar 1987

Anschriften der Verfasser: Prof. Dr. St. Dramanroglo, Institute of General Botany, University of Athens, Panepistimiopolis, GR - 15784 Athen; Prof. Dr. U. KrLr, Biologisches Institut der Universitat Stuttgart, Clmer Straße 227, D - 7000 Stuttgart. 